\title{
TÉCNICA(S), ARTIFICIALIDAD Y NATURALEZA
}

\section{Sergio Cecchetto*}

\section{Introducción}

Bajo la forma de breves tesis he querido hilvanar algunas reflexiones en torno a un texto del filósofo argentino Ricardo Maliandi, publicado hace ya veinticinco años atrás. El trabajo, que lleva por título "Natura abscondita. Los resortes naturales de la técnica", vio la luz en la revista Escritos de Filosofia ${ }^{1}$ y se insertó más tarde dentro del volumen Cultura y conflicto investigaciones éticas $y$ antropológicas -2 , pero a pesar de su inactualidad se constituye en una muy buena pieza de antropología filosófica.

Trataré de ir exponiendo primero alguna de las ideas centrales del autor y, a manera de contrapunto final, sumaré mis propias observaciones y digresiones sobre el particular.

\section{Técnica, naturaleza y antropología}

2.1. Un rasgo que Maliandi le atribuye a la técnica moderna -maquinista- en el escrito citado, pero que se ha mantenido presente en otros escritos posteriores, es su carácter jánico, ambivalente, ambiguo. Según se ponga el acento en lo "natural" o en lo "artificial" del concepto de "técnica", es que sin mayor trámite se lo coloca por derecho propio entre los fenómenos de la naturaleza (vitales) o en el mundo de la artificialidad antivital, de lo extranatural por excelencia. Resta por saber, entonces, si la llamada técnica humana es apenas un grado cuantitativamente diverso de otra técnica ya presente en el mundo pre-cultural, o si bien la técnica humana denota un salto cualitativo que la torna esencialmente diversa de su antecesora.

* CONICET-Univ. Nac. de Mar del Plata; scypu@infovia.com.ar

1 Maliandi, R., "Natura abscondita. Los resortes naturales de la técnica", Escritos de Filosofia II -4-, 1979: 35 y ss.

2 Maliandi, R., Cultura y conflicto -investigaciones éticas y antropológicas-, Biblos, Buenos Aires, 1984, pp. 109-130 
2.2. Las valoraciones que luego se hacen del fenómeno técnico se inclinan hacia la fascinación tecnofilica y el encandilamiento cuando se contemplan logros positivos alcanzados por su concurso, o aparecen por el contrario actitudes tecnofóbicas y temores antitecnicistas más o menos fundados cuando se toman en consideración fenómenos disvaliosos, indeseados, adversos, colaterales. A la ambigüedad ontológica de la técnica (v.g. la dificultad de saber lo que la técnica propiamente es), se le suma entonces una ambigüedad axiológica (v.g. la dificultad de saber cómo debe valorársela). Para Maliandi en definitiva " $\mathrm{la}$ ambigüedad de la técnica viene a coincidir con la del hombre..." (p. 110), y esto en los dos sentidos mencionados, el ontológico y el axiológico.

2.3. Las siguientes páginas del escrito de Maliandi trazan un paralelo entre el proceso ("natural") de hominización y el del despliegue técnico en relación a la naturaleza para, a partir de datos aportados por distintas disciplinas científicas (biología, anatomía, fisiología, genética, paleontología, antropología, historia, lingüística, etc.), desentrañar cómo el devenir biológico del género Homo a lo largo de millones de años permitió la aparición de cultura técnica (instrumentos, aparatos, materiales, dispositivos, técnicas, máquinas, etc.). La constitución del hombre actual, entonces, es a la vez la constitución y construcción de una segunda naturaleza, ésta de carácter técnico, que le permite ser al hombre propiamente lo que es. Y por la contraria, estas modificaciones en el hombre, repercuten directamente sobre el mundo técnico, azuzando nuevos desarrollos.

2.4. Maliandi adhiere sin mayores reparos a la tesis de la compensación esbozada por Protágoras y exhaustivamente desmenuzada por Arnold Gelhen. La técnica aparece así como forma ortopédica de compensar ciertos defectos originarios del hombre, cierta inespecificidad biológica intrínseca, cierta "falla" o imperfección natural, cierta inespecialización orgánica que lo aqueja, y le permite de esta manera trocar en ventajas la desventaja inicial. En cualquier caso este recurso técnico no se contenta con restablecer el equilibrio sino que sobre-compensa, o lo hace en exceso, trocando la mera condición en estimulo perpetuo que sobrepasa los niveles elementales de funcionamiento aceptable. Este plus compensatorio de las carencias hominizantes sienta las bases de la humanización, entendida como "desarrollo de la capacidad para la acción desinteresada de las naturales urgencias de la vida" (p. 119). 
2.5. La inespecialización humana (indeterminación biológica) se traduce en especialización generalizada, en aptitud para casi cualquier cosa. La técnica viene a ofrecerse, entonces, como auxiliar de un nuevo recurso evolutivo, pues se conecta con características biológicas esenciales de la especie hombre: el bipedestrismo, la locuacidad y la manidiestra disposición. La técnica posee, en esta perspectiva, un doble carácter, a la vez natural y artificial: natural en cuanto surge para paliar un defecto naturalmente creado, $\mathrm{y}$ artificial en tanto da respuesta compensatoria por medio de un artefacto cultural al defecto de base. En otras palabras, la técnica exhibe en cualquiera de sus despliegues su natural raíz y la artificialidad de sus frutos. Y el Homo deviene hombre y hacedor (faber) aprovechando la "diferencia" de su minusvalía orgánica frente al resto de los animales, en el intersticio naturacultura.

2.6. Ahora bien, ambos procesos, hominización y humanización tienen que encontrar y mantener un justo equilibrio para poder hablar de manera cabal de "humanización de la técnica", de comprensión (Versteben) acabada de la técnica es decir, de una mirada hominizante y humanizante teleológicas y no reductivas que sitúen a la técnica dentro de la esfera de la naturaleza, que la inserten en la naturaleza. La naturaleza mientras tanto ha de permanecer incomprensible, en tanto se trata de una instancia no teleológica-ya que no posee fines propios- de la cual desconocemos su "para qué". Podemos tener visiones, registro, captación, experiencia y hasta hacer exploración e investigación sobre la naturaleza, pero en todos los casos ella se sustrae a la comprensión espiritual, como no sea para permitir ser integrada como una realidad in-comprensible.

2.7. Huelga decir que la conflictividad se hace presente en todos estos procesos comprensivos, valorativos; y también en la consideración misma de la técnica, de la naturaleza, de los fenómenos vitales, de la razón y del hombre. Tanto la realidad cultural como la natural, en opinión del autor, se desenvuelven a través de conflictos, y éstos son parte constitutiva de la dinámica cósmica. Estas relaciones "de mutua incompatibilidad o exclusión entre dos o más elementos de un conjunto" (p. 9) rigen todas las reflexiones anteriores, las enmarcan y les otorgan movimiento, en tanto son pauta que "explica" los desequilibrios, las discordancias y las transformaciones.

Hasta aquí una muy ajustada síntesis del trabajo mencionado, necesariamente apretada e intencionada, ya que a continuación pretendo 
realizar una serie de observaciones propias surgidas de la lectura y de la reflexión sobre este material.

\section{Técnica(s) y evolucionismo}

Volveré a numerar ahora las apostillas, iniciando el listado con consideraciones metodológicas o de enfoque, y continuando luego con otras que refieren a cuestiones antropológicas y evolutivas propiamente dichas.

3.1. El procedimiento antropológico y ético elegido por Maliandi para dar cuenta de las raíces naturales de la técnica y su vinculación íntima con el zoón anthropos exhibe la actual tendencia a biologizar estas materias es decir, a pensarlas bajo el molde que nos ofrecen las disciplinas bio-médicas contemporáneas. La fabulación sobre el hombre y sus orígenes fue pasto de la mitología y, oportunamente, de la teología. Al parecer ahora, los esquemas de trabajo se han arrimado a otro grupo de disciplinas científicas, y son ellas las que definen los campos significativos y los objetos que han de entrar en consideración.

3.2. La doctrina evolucionista parece estar a la base de todas las elucubraciones del autor, y ella toma el lugar del origen, de relato constitutivo primigenio, de metafísica inconfesada. Haría justicia advertir en el texto analizado que azar y necesidad son conceptos tan hipotéticos, en última instancia, como los de finalidad y creación. La concepción naturalista del mundo ha caído en desuso, pero la "explicación" biologista no la suplanta con solvencia. En tanto cualquiera de ellas aparece con pretensión exclusiva de verdad, deviene ideología.

3.3. Podríamos preguntarnos, con licitud, si el recurso evolucionista es una buena figura para explicar la "historia" de la técnica. Esto porque, a diferencia de los animales que se adaptan al medio para subsistir (de acuerdo con la tesis evolucionista tradicional), la técnica humana es en cambio capacidad para aumentar el poderío y la inventiva de los hombres. Así miradas las cosas, la técnica es anti-evolucionista, pues el propio medio se ve en la necesidad de adaptarse a las pretensiones de un sujeto. Además, la cultura misma no es una realidad que aparezca en la línea de la evolución biológica ni tampoco como el coronamiento de una especialización antropológica, sino, más bien, en virtud de una forma somática 
inespecializada, abierta, indeterminada, "no fijada" para utilizar la expresión de Nietzsche ("nicht festgestelltes Tier").

3.4. Maliandi recurre a una especie de retro-ingeniería (reverse inginnering), a una hermenéutica de lo viviente para ofrecernos una historia plausible de los orígenes de la técnica humana, similar a la que utilizan los arqueólogos, los historiadores o los biólogos evolutivos. Este enfoque parte del supuesto de que existe un principio de racionalidad en los actores afectados, los cuales tiene objetivos, conocimientos, valores, preferencias, opciones, etc. La técnica sería así el resultado de un sistema intencional, perteneciente al individuo o grupo que la creó.

Se puede proponer esta perspectiva intencional y seguir luego a través de dos vías de análisis posibles y complementarias: o la acción humana y sus productos son las resultantes de una opción entre medios disponibles para la obtención de un determinado fin o meta; o bien es el resultado de un cálculò sostenible entre costos y beneficios ${ }^{3}$. En otras palabras, Maliandi no busca explicar tan sólo hipotéticamente por qué algo ocurrió de una determinada manera (búsqueda de causas), sino que de soslayo apunta a mostrar por qué eso pudo ser mejor que alguna otra alternativa que también estaba presente en la situación que estudia (búsqueda de razones de ser). Dicho de otro modo, todavía: no se contenta con saber qué es lo que el hombre hace valiéndose de la técnica, sino en qué sentido eso que hace resulta mejor que alguna de las otras alternativas que dejó oportunamente a un lado. Así, las cosas fueron como fueron y están hoy donde están porque su presencia implicó -en algún momento- un beneficio mayor que el que implicaba su ausencia; o aceptando el segundo enfoque citado más arriba, perduran porque retenerlas implica menos costos que abandonarlas.

Para nosotros esas razones son siempre razones de alguien, de un agente intencional, de un sujeto. ¿Quién es el sujeto aquí? De seguro la respuesta no apunta a un antropomorfismo grosero y metafísicamente ya superado. Concibo sólo otras dos opciones: Maliandi trata de personificar una especie y la trata como a un razonador práctico (Homo), o tiene en mente a la selección natural como concepto análogo al de Madre Naturaleza (sistema intencional

3 Caponi, G., "La sabiduría de las especies. Las poblaciones biológicas como sistemas cognitivos", Ludus Vitalis 10 (18) 2002: 3-25. Seguiremos a este autor en el análisis que realizamos. 
que es el "responsable" por la evolución biológica). En este segundo caso tendríamos un sustituto laico del dios de Paley en su teología natural, aunque le llamáramos ingeniero (Dobzhansky), relojero ciego (Dawkins) o bricoleur (Jacob). Sospecho, en cualquier caso, que el sujeto intencionado que buscamos se encontraría mejor representado por el concepto de especie, y mejor todavía por el de poblaciones, ya que son los linajes o secuencias de éstos los que resuelven los problemas adaptativos. Ni la Naturaleza, ni la Selección Natural, ni la Especie cumplen con este papel: son las poblaciones las que exploran y evalúan todo el universo de soluciones disponibles para dar cuenta de los distintos problemas adaptativos que cuestionan su permanencia en el tiempo.

3.5. El fascinante argumento del "animal no terminado", del ser que es tarea para sí mismo en tanto necesita sobreponerse técnicamente a sus deficiencias específicas (no-adaptación, no-especialización, no-evolución, primitivismo, etc.), no es jamás del todo convincente. Esto porque presenta a las deficiencias del hombre como un hecho absolutamente negativo, lo cual no es nunca cierto. La inespecificidad es una característica relativa, que surge por comparación entre el hombre y el resto de los animales: éste posee lo que aquellos no tienen, y viceversa. $Y$ además, se trata en todos los casos de una nota positiva, a pesar de que pueda vérsela como contraria si oponemos la realidad humana a la de otros seres vivientes.

3.6. ¿Podemos con licitud, sobre la base de una negatividad biológica, dar cuenta de la humanización del Homo? ¿Las acciones desinteresadas "de las naturales urgencias de la vida", son producto de la inespecificidad de la especie? ¿El espíritu es hijo de la carencia? ¿El cuerpo es otra vez materialidad menospreciada, insuficiente y pobre, redimida apenas por el surgimiento del glorioso espíritu, única entidad digna de elogio? Entiendo que puede plantearse, más bien, por el contrario, que el plus antropológico esfera espiritual- cuenta con un sustrato biológico, pero que éste ha de ser comprendido siempre como positividad, como realidad plena y operante.

Así, por ejemplo, puede continuarse en la antigua línea que propone al soma del hombre como sustrato "natural" de la ética, en tanto este animal inadaptado necesita encontrar justificaciones y regulaciones externas a su conducta, puesto que no dispone de pautas biológicas fijas a las cuales obedecer. $\mathrm{O}$ puede interpretarse la misma cuestión desde otro ángulo, 
ofreciendo la posibilidad de que la aparición de los cuerpos normativos sean creación, invención libre y legitimación antropológica.

Sumaré todavía algunas pocas observaciones más sobre el tema técnico, por entender que el artículo que estudiamos aporta consideraciones interesantes en torno de él, aunque no siempre he sido capaz de compartirlas en plenitud.

3.7. Entiendo que por momentos la nomenclatura tradicional utilizada por Maliandi para referirse al problema técnico se convierte en un escollo para entender el tema a explorar. Hablar sin más de la técnica puede llevar a equívocos en tanto se entifica o cosifica esta noción, se la sustantiviza. Quizá sería más conveniente transitar otras expresiones idiomáticas, tal vez con menor tradición filosófica pero sin duda con mayor "efecto desnaturalizador". Por ejemplo, podría ensayarse la referencia a lo técnico como megaproblema (conservando no sólo su neutralidad sustantiva sino también su ambigüedad ontológica y valorativa), y utilizar la palabra técnicas siempre en plural, como manera de indicar las distintas técnicas siempre particulares.

3.8. Me encuentro en un todo de acuerdo respecto de la artificialidad constitutiva del hombre contemporáneo, inserto de lleno en el mundo cultural para existir y subsistir. El mundo humano forma un peculiar espacio hermenéutico, en el cual el objeto hombre -ente natural/artificial- vive sumergido entre objetos de corte técnico, y sólo es capaz de observar ese patio de objetos que lo rodea con instrumentos y nociones de cuño instrumental. Esta forma de vinculación ha recibido el mote de "concepción tecnológica del mundo"4, y ha sido recusada por ser un caso particular de "ocultación del ser" y, sin duda ninguna, de ocultación de la naturaleza. Omnipresente en el texto estudiado es la captación de lo técnico siempre bajo el molde de lo protésico o de lo instrumental, para utilizar la nomenclatura ya clásica elaborada por Martin Heidegger. Un acercamiento de tal índole a la cuestión de lo técnico imposibilita una comprensión del problema en términos ontológicos.

${ }^{4}$ De seguro esta perífrasis esquiva la utilización de nociones imprecisas tales como pensamiento técnico, en el convencimiento de que probablemente lo técnico opera, pero no piensa. 
No pretendo con este señalamiento proponer que lo técnico con su despliegue planetario sea una nueva forma de absoluto, como algunos pensadores contemporáneos han sugerido, entiendo que erróneamente. No son el hombre ni la naturaleza los que hacen lo técnico, tal como yo lo veo, más bien se da la situación contraria: ambas instancias son producidas técnicamente $(t e ́ k n e)^{5}$ o, dicho de otra manera más sugerente y precisa, ambas son fragmentario pensamiento y poeticidad (póiesis). Lo técnico es capaz de cerrar las vías de poeticidad, pero también de abrirlas, al establecer nuevas posibilidades relacionales entre hombre y mundo, probablemente caras de una sola moneda siempre en diálogo. Pero, a diferencia de los antiguos absolutos (Phýsis, Theós, Antbropos), lo técnico no otorga una unidad de sentido a lo que aparece, no ofrece una clave de inteligibilidad y, por supuesto, no promete que de su despliegue arrollador devendrán solamente bienes para todos los hombres.

\section{Una conclusión que no concluye}

Apenas algunas veces la vida académica nos depara la posibilidad de discutir por escrito opiniones de interlocutores cuya producción, meditada y sesuda, es contemporánea de la nuestra. Esta publicación lo permite ahora, y ambas visiones del mundo -separadas por veinticinco años de distanciaentran en diálogo y disienten sobre ideas, sin necesidad ninguna de guardarles un respeto reverencial. Permanece sin embargo la íntima sospecha de que ninguna de ellas dispone de la última palabra, y de que se trata en definitiva de un diálogo inacabado y necesariamente inacabable ${ }^{6}$.

\section{A Ricardo Maliandi, maestro y amigo}

${ }^{5}$ Me resisto a utilizar en este contexto la palabra creación.

${ }^{6}$ Este escrito fue elaborado y discutido con ocasión de las Jomadas sobre Ética, Razón y Conflictividad, llevadas adelante en la ciudad de Mar del Plata por el Consejo Regional Buenos Aires de la Asociación Argentina de Investigaciones Eticas, en mayo de 2004, a la manera de homenaje al Prof. Dr. Ricardo Maliandi y a su obra escrita. 


\section{Resumen}

Esta comunicación resume primero y analiza después con cierto detalle un escrito de Ricardo Maliandi sobre los resortes naturales de la técnica (1979), haciendo consideraciones de método, cuestionamientos antropológicos y éticos, sentando otros reparos luego respecto del sentido y alcance de lo técnico en relación con la evolución del hombre.

Palabras Clave: "Naturaleza", "técnica”, “antropología”, “ética”, "Evolucionismo".

\section{Abstract}

This paper presents a short review and then examines in some detail a text by Ricardo Maliandi (1979) on the natural motives of technique. It offers/provides methodological considerations and raises anthropological and ethical issues, casting doubt about the sense and scope of the technical in relation to human evolution. Key Words: "Nature”, "technique”, “anthropology", “ethics", “evolutionism". 